\title{
Bonding durability of custom-made mouthpiece for scuba diving after water storage under pressure
}

\author{
Chie IHARA ${ }^{1}$, Hidekazu TAKAHASHI ${ }^{2}$, Ryosuke MATSUI ${ }^{1}$, Takuto YAMANAKA ${ }^{1}$ and Toshiaki UENO ${ }^{1}$ \\ ${ }^{1}$ Sports Medicine/Dentistry, Department of International Health Development, Graduate School of Medical and Dental Sciences, Tokyo Medical and \\ Dental University, 1-5-45 Yushima, Bunkyo-ku, Tokyo, 113-8549, Japan \\ ${ }^{2}$ Advanced Biomaterials, Department of Restorative Sciences, Graduate School of Medical and Dental Sciences, Tokyo Medical and Dental University, \\ 1-5-45 Yushima, Bunkyo-ku, Tokyo, 113-8549, Japan \\ Corresponding author, Chie IHARA; E-mail: ihachie.spmd@tmd.ac.jp
}

\begin{abstract}
The purpose of this study was to assess the behavior of laminated thermoforming materials in an underwater environment to understand the durability of mouthpieces for scuba diving. Two thermoforming materials, polyolefin (PO) and ethylene-vinyl acetate copolymer (EV), were laminated and stored in air, $37^{\circ} \mathrm{C}$ water, and $37^{\circ} \mathrm{C}$ water under $0.2-\mathrm{MPa}$ pressure for 1 and $4 \mathrm{weeks}$. The load/ bonding width (bonding strength: BS) and displacement at the start of delamination (SD) and fracture (FR) were analyzed with 3-way ANOVA. BS values at SD and FR in air were significantly greater than those under the other conditions, and the BS at SD of EV was significantly greater than that of $\mathrm{PO}$, though the effects of materials, duration and their interactions were not significantly different. The displacements at SD and FR were significantly influenced by the material. These results suggest that both materials can be employed for making a diving custom mouthpiece.
\end{abstract}

Keywords: Bonding durability, Custom-made mouthpiece, Water storage under pressure

Received Nov 26, 2008: Accepted Feb 12, 2009

\section{INTRODUCTION}

Scuba diving is a popular sport that many people enjoy. In recent years, the number of scuba divers has been growing ${ }^{1)}$. However, scuba diving may trigger problems in some parts of the body such as the nose, ear, lung, and temporomandibular joint ${ }^{2-6)}$. Previous studies reported that the prevalence of temporomandibular disorders while scuba diving ranged from $24 \%$ to $68 \%{ }^{7-10}$. The most common problems during or after the scuba diving are temporomandibular disorders (TMD) ${ }^{11}$. This type of TMD might be caused by not only environmental factors such as cold water8), but also the forward posturing of the mandible while holding and clenching a mouthpiece for a long time ${ }^{3,12)}$. Therefore, beginner divers complain of TMD problems related to the mouthpiece more often than experts ${ }^{13)}$. Thus, a welldesigned custom mouthpiece is recommended for relieving and preventing TMD.

In our previous report, a new lamination forming technique using polyolefin thermoforming materials to fabricate a custom scuba-diving mouthpiece was introduced ${ }^{14)}$. Both polyolefin and ethylene-vinyl acetate copolymer are commonly used sports mouthguard materials. The mouthpiece for scuba diving is exposed to water for a long time compared to mouthguards for other sports. Therefore, the mouthpiece for scuba diving is exposed to stress by biting and external force while the diver is underwater and surfacing. These stresses cause the mouthpiece to be damaged. A damaged mouthpiece is very dangerous, because the diver may not be able to breathe. However, the durability of custom scuba-diving mouthpiece materials under water has not been clarified. The purpose of the present study was to assess the bonding behavior, tear strength and water absorption of laminated thermoforming materials in an underwater environment in an effort to understand the durability of the mouthpiece for scuba diving.

The null hypotheses of the present study were that the bonding and tear strengths of polyolefin and ethylene-vinyl acetate copolymer used as mouthpiece materials did not decrease after underwater storage.

\section{MATERIALS AND METHODS}

\section{Materials}

Two types of commercial thermoforming-sheet materials for mouthguard, polyolefin clear and colored (PO: MG21, Molten Co., Hiroshima, Japan; Clear: Lot No. 1228004, Pink: 0330004) and ethylene-vinyl acetate copolymer clear and colored (EV: Mouthguard Sheet, Ultradent Co., Utah, USA; Clear: Lot No. B253H, Yellow: 59GC), were selected. Polyolefin is an ethylene propylene thermoplastic elastomer ${ }^{15}$.

\section{Delamination test}

A T-peel test was used as the delamination test ${ }^{16,17)}$. Two sheets of the same mouthguard material in different colors were laminated together. Two filmshaped sheets for separation (Molteno Separate Film, Molten Co., Hiroshima, Japan) were placed on one mouthguard sheet to create an adhesive area so that the center of the sheet had a width of $15 \mathrm{~mm}$. Then the other mouthguard sheet was heated and placed in a vacuum at $0.012 \mathrm{MPa}$ when the sheet was hung 15 $\mathrm{mm}$ from the center using a vacuum thermoforming machine (Vacuum Forming Machine, Keystone Industries. Cherry Hill, NJ, USA) ${ }^{18)}$. The laminated sheet was cut with a dumbbell-shaped cutter according 
to JIS K6251:2004 so that the adhesive area was at the center of the isthmus, and sectioned at the center of the isthmus. The final specimens for delamination, with an adhesive area of $4.0 \mathrm{~mm} \times 7.5 \mathrm{~mm}$, are shown in Figs. 1 and 2. Thirty specimens of each material were prepared and assigned into the following three groups.

Group 1. Storage in a container in the laboratory (23 $\pm 2^{\circ} \mathrm{C}$ ) (hereafter referred to as in air)

Group 2. Storage in water in a glass beaker in a $37^{\circ} \mathrm{C}$ thermostatic chamber (Advantec CI-610, Toyo Seisakusho Co., Tokyo, Japan) (hereafter referred to as in water).

Group 3. Storage in water in a pressure pot (New Pressure Pot, Mokuda Shokai, Kobe, Japan) in a $37^{\circ} \mathrm{C}$ thermostatic chamber. The pressure was controlled to under $0.2 \mathrm{MPa}$ (hereafter referred to as in $0.2 \mathrm{MPa}$ water).

After 1 and 4 weeks in the above-mentioned storage conditions, the specimens were subjected to a delamination test. The size of the specimen was measured using a digital micrometer (Digimatic 293421-20, Mitutoyo, Kanagawa, Japan. Minimum reading: $0.001 \mathrm{~mm})$. The specimen was fixed to a universal test machine (1123, Instron, Canton, MI, USA) with a special jig to grip it firmly. The delamination test was carried out with the universal test machine at a crosshead speed of $50 \mathrm{~mm} / \mathrm{min}$ (Fig. 3). Changes of load and displacement until the specimen fractured were recorded with statistical software (Series IX, Instron).

A typical load-displacement curve is shown in Fig. 4. The load rapidly increased when delamination started. The bonding strength at the start of delamination (BS at SD) was calculated as the load at the start of delamination divided by the width of the specimen (approximately $4.0 \mathrm{~mm}$ ). The load at the start of delamination was determined as the load of the cross point of the initial slope and the second slope of the load-placement curve (Fig. 4). The displacement at the start of delamination (displacement at SD) was also measured. The bonding strength at fracture (BS at FR) was calculated as the load at fracture divided by the width of the specimen. The displacement at fracture (displacement at FR) was also recorded.

\section{Tear strength test}

Unnicked angle-shaped specimens formed according to JIS K6252: 2004 were used for the tear strength test (Fig. 1). The specimens were cut from the original sheet using an angle-shape cutter. Thirty specimens of each material were prepared, and assigned into three groups in the same manner as for the delamination test. After storage, the thickness of the specimen was measured using a digital micrometer and it was subjected to the tear test using the universal test machine at a cross-head speed of $500 \mathrm{~mm} / \mathrm{min}$. Changes of load and displacement until the specimen fractured were recorded. The load/specimen thickness and displacement at the fracture were registered as the tear strength and tear displacement, respectively.

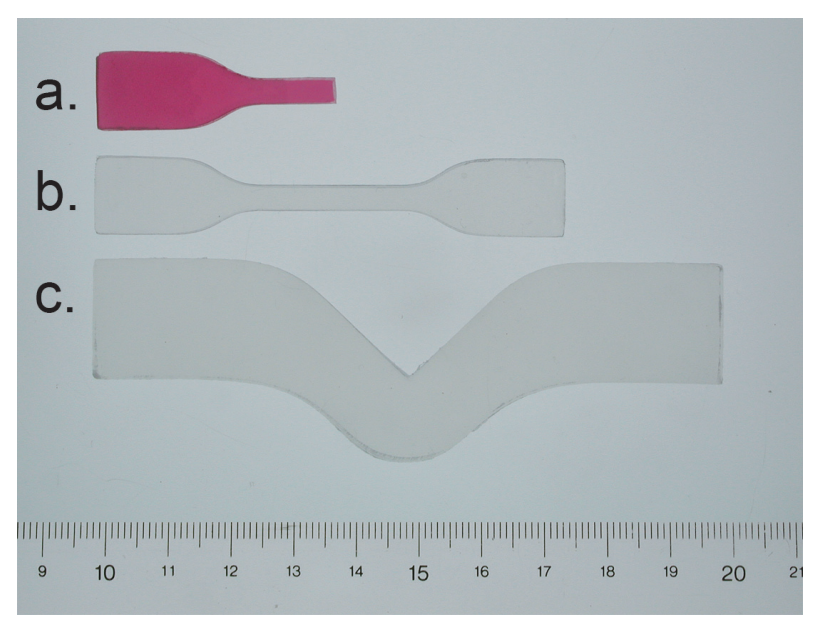

Fig. 1 Specimens used. a: delamination test, b: water sorption, c: tear strength test.

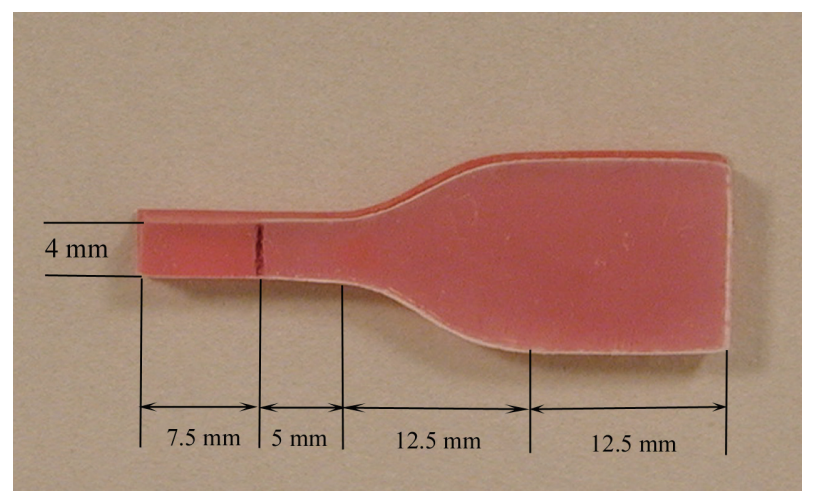

Fig. 2 Dimensions of the specimens for the delamination test $(\mathrm{mm})$. The only left parallel portion of $7.5 \mathrm{~mm}$ was laminated.

Water sorption and solubility

Water sorption and solubility of the dumbbell-shaped specimens were measured (Fig. 1). Ten specimens were prepared for each material using the above-mentioned dumbbell-shaped cutter. The weight of each specimen after storage in a desiccator containing freshly dried silica gel was measured until the change of weight was less than $0.2 \mathrm{mg} /$ day with a precise balance (Mettler Toledo AG245, Greifensee, Switzerland; minimum reading $0.1 \mathrm{mg})$, and recorded as a constant mass $\left(m_{0}\right)$. Then specimens were stored in the above-mentioned conditions in water or in 0.2 $\mathrm{MPa}$ water. After 4-week storage, specimens were removed from the water with a pair of polymer-coated tweezers, wiped with a clean dry paper towel until free from visible moisture, waved in the air for $15 \mathrm{~s}$, and weighed at $60 \mathrm{~s}$ after removal from the water. Results were recorded as $m_{1}$. After 


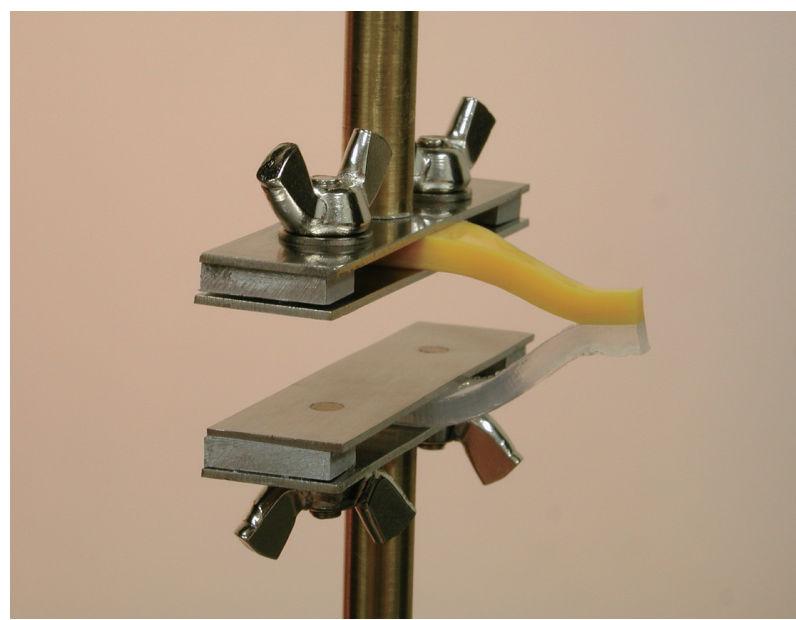

Fig. 3 Delamination test was carried out using a universal test machine with a special jig to grip the specimen.

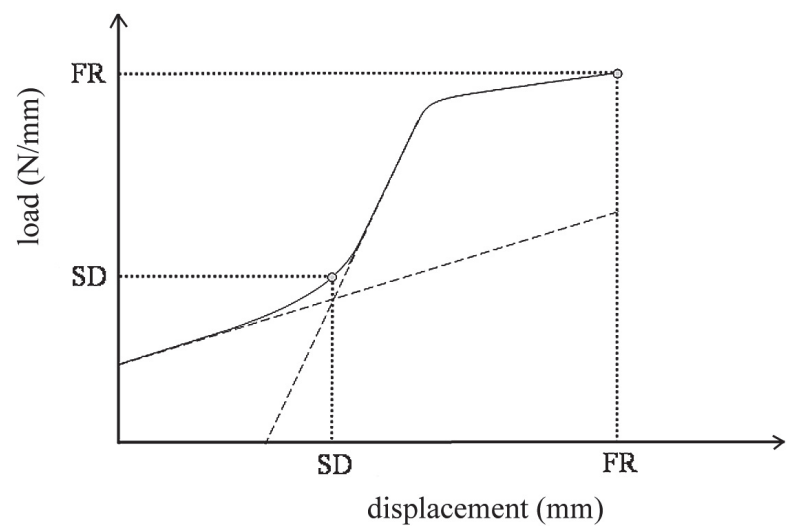

Fig. 4 Typical load-displacement curve of delamination. SD: the point at the start of delamination, FR: fracture point $m_{1}$ measurement, the weight of each specimen was remeasured until it reached a constant mass in the desiccator. The weight of the reconditioned specimen was recorded as $m_{2}$.

Water sorption after 4-week storage (WS) was calculated in micrograms from the following equation:

$$
\mathrm{WS}=m_{1}-m_{2}
$$

Solubility, $S B$, leaching out during immersion, was expressed in micrograms and calculated for each specimen using the following equation:

$$
\mathrm{SB}=m_{0}-m_{2}
$$

\section{Statistical analysis}

The bonding strength and the displacement at SD and FR of the delamination test and the tear strength were statistically analyzed with 3 -way analysis of variance (ANOVA) and Tukey's post-hoc test $(p<0.05)$ using statistical software (JMP IN 5.1, SAS Japan, Tokyo). The water absorption and solubility were analyzed with 2-way ANOVA.

\section{RESULTS}

There were no obvious changes of the specimens after storage that could be recognized by the naked eye.

Delamination test

Bonding strengths (BS) and displacements are summarized in Table 1.

Regarding BS at the start of delamination (SD), the storage condition and material had significant effects, but the other factors did not. BS at SD stored in air, $5.27 \mathrm{~N} / \mathrm{mm}$, was significantly greater than that in water, $4.50 \mathrm{~N} / \mathrm{mm}$, and in $0.2 \mathrm{MPa}$ water, $4.36 \mathrm{~N} /$ $\mathrm{mm}$. The BS at SD of EV, $5.46 \mathrm{~N} / \mathrm{mm}$, was significantly greater than that of PO, $3.96 \mathrm{~N} / \mathrm{mm}$.

Regarding displacement at SD, there was a significant difference between the materials. The value

\begin{tabular}{|c|c|c|c|c|c|c|c|}
\hline & & \multicolumn{2}{|c|}{ in air } & \multicolumn{2}{|c|}{ in water } & \multicolumn{2}{|c|}{ in $0.2 \mathrm{MPa}$ water } \\
\hline & & $\mathrm{PO}$ & $\mathrm{EV}$ & $\mathrm{PO}$ & $\mathrm{EV}$ & $\mathrm{PO}$ & $\mathrm{EV}$ \\
\hline \multirow{2}{*}{$\begin{array}{l}\mathrm{BS} \text { at } \mathrm{SD} / \\
\mathrm{N} / \mathrm{mm}\end{array}$} & 1 week & $4.50(0.48)$ & $6.35(1.20)$ & $4.12(0.25)$ & $5.21(0.79)$ & $3.79(0.43)$ & $5.25(1.22)$ \\
\hline & 4 weeks & $4.21(0.28)$ & $6.03(0.68)$ & $3.64(0.57)$ & $5.04(0.81)$ & $3.53(1.05)$ & $4.87(0.38)$ \\
\hline \multirow{2}{*}{$\begin{array}{l}\text { Displacement } \\
\text { at } \mathrm{SD} / \mathrm{mm}\end{array}$} & 1 week & $19.1(0.5)$ & $18.4(1.3)$ & $19.2(0.5)$ & $17.9(0.9)$ & $18.5(1.1)$ & $17.4(1.3)$ \\
\hline & 4 weeks & $19.7(1.1)$ & $18.3(1.2)$ & $18.8(1.4)$ & $18.4(1.1)$ & $19.6(1.8)$ & $18.1(1.8)$ \\
\hline \multirow{2}{*}{$\begin{array}{l}\mathrm{BS} \text { at FR/ } \\
\mathrm{N} / \mathrm{mm}\end{array}$} & 1 week & $8.33(1.47)$ & $8.47(0.70)$ & $6.78(0.10)$ & $7.36(1.50)$ & $7.65(0.61)$ & $6.11(1.90)$ \\
\hline & 4 weeks & $7.29(0.84)$ & $7.36(0.46)$ & $7.34(0.54)$ & $6.73(1.77)$ & $7.14(0.50)$ & $6.37(1.66)$ \\
\hline \multirow{2}{*}{$\begin{array}{l}\text { Displacement } \\
\text { at FR / mm }\end{array}$} & 1 week & $142.0(22.9)$ & $65.7(9.9)$ & $100.4(14.6)$ & $61.4(7.0)$ & $131.3(12.6)$ & $49.2(7.7)$ \\
\hline & 4 weeks & $138.5(33.8)$ & $58.0(3.4)$ & $133.2(32.4)$ & $60.2(20.1)$ & $124.6(21.9)$ & $56.3(10.6)$ \\
\hline
\end{tabular}

Table 1 Results of the delamination test

BS: Bond strength, SD: the point at the start of delamination, FR: fracture point 
Table 2 Results for the fracture pattern of the delamination test (interfacial fracture/cohesive fracture)

\begin{tabular}{|c|c|c|c|c|c|c|}
\hline & \multicolumn{3}{|c|}{$\mathrm{PO}$} & \multicolumn{3}{|c|}{$\mathrm{EV}$} \\
\hline & in air & in water & in $0.2 \mathrm{MPa}$ water & in air & in water & in $0.2 \mathrm{MPa}$ water \\
\hline 1 week & $3 / 2$ & $5 / 0$ & $4 / 1$ & $5 / 0$ & $5 / 0$ & $5 / 0$ \\
\hline 4 weeks & $3 / 2$ & $2 / 3$ & $4 / 1$ & $5 / 0$ & $5 / 0$ & $5 / 0$ \\
\hline
\end{tabular}

Table 3 Results of the tear test

\begin{tabular}{|c|c|c|c|c|c|c|c|}
\hline & & \multicolumn{2}{|c|}{ in air } & \multicolumn{2}{|c|}{ in water } & \multicolumn{2}{|c|}{ in $0.2 \mathrm{MPa}$ water } \\
\hline & & $\mathrm{PO}$ & $\mathrm{EV}$ & $\mathrm{PO}$ & $\mathrm{EV}$ & $\mathrm{PO}$ & $\mathrm{EV}$ \\
\hline \multirow{2}{*}{$\begin{array}{l}\text { Tear strength } \\
\mathrm{N} / \mathrm{mm}\end{array}$} & 1 week & $53.0(2.0)$ & $58.9(1.3)$ & $49.0(1.0)$ & $52.3(1.8)$ & $48.7(0.4)$ & $51.7(3.0)$ \\
\hline & 4 weeks & $52.1(0.4)$ & $55.8(1.0)$ & $49.8(0.5)$ & $55.7(0.7)$ & $50.5(0.7)$ & $53.7(3.0)$ \\
\hline \multirow{2}{*}{$\begin{array}{l}\text { Displacement } \\
\mathrm{mm}\end{array}$} & 1 week & $152.7(11.0)$ & $128.2(22.0)$ & $149.7(5.6)$ & $127.8(22.8)$ & $147.0(4.3)$ & $125.0(18.4)$ \\
\hline & 4 weeks & $151.0(4.8)$ & $124.8(18.7)$ & $154.2(9.4)$ & $135.2(8.1)$ & $162.8(7.1)$ & $128.5(12.6)$ \\
\hline
\end{tabular}

Table 4 Results for water sorption and solubility

\begin{tabular}{|c|c|c|c|c|c|c|c|c|}
\hline \multirow[b]{3}{*}{ WS (mg) } & \multicolumn{4}{|c|}{ in water } & \multicolumn{4}{|c|}{ in $0.2 \mathrm{MPa}$ water } \\
\hline & \multicolumn{2}{|c|}{$\mathrm{PO}$} & \multicolumn{2}{|c|}{$\mathrm{EV}$} & \multicolumn{2}{|c|}{$\mathrm{PO}$} & \multicolumn{2}{|c|}{$\mathrm{EV}$} \\
\hline & 0.1 & $(0.2)$ & 3.9 & $(0.6)$ & 0.2 & $(0.2)$ & 6.0 & (2.1) \\
\hline $\mathrm{SB}(\mathrm{mg})$ & 0.1 & $(0.2)$ & 0.2 & $(0.1)$ & -0.1 & $(0.1)$ & -0.1 & $(0.2)$ \\
\hline
\end{tabular}

WS: water sorption after 4 weeks, SB: water solubility

for PO, $19.2 \mathrm{~mm}$, was significantly greater than that for $\mathrm{EV}, 18.6 \mathrm{~mm}$. The other factors and their interactions were not significantly different.

$\mathrm{BS}$ at $\mathrm{FR}$ showed significant differences among the storage conditions as for $\mathrm{BS}$ at $\mathrm{SD}$. BS at $\mathrm{FR}$ for materials stored in air, $7.86 \mathrm{~N} / \mathrm{mm}$, was significantly greater than that for those stored in water, $7.05 \mathrm{~N} / \mathrm{mm}$ and in $0.2 \mathrm{MPa}$ water, $6.82 \mathrm{~N} / \mathrm{mm}$. The other factors and their interactions were not significantly different.

Statistical analysis of the displacement at FR showed the same results as that at SD. Displacement at FR of PO, $128.3 \mathrm{~mm}$, was significantly greater than that of EV, $58.4 \mathrm{~mm}$. The other factors and their interactions were not significantly different.

The delaminated surfaces are classified in Table 2. All delaminated EV surfaces showed interfacial fracture, and one-third of delaminated surfaces of PO exhibited cohesive failure.

\section{Tear strength test}

All specimens after the tear strength test were broken at the center portion. Tear strength and tear displacement are presented in Table 3. Regarding tear strength, 3-way ANOVA revealed that the storage condition, material, and the interaction of the storage condition and storage period significantly affected the results of the test. The estimated tear strength in air,
$54.9 \mathrm{~N} / \mathrm{mm}$, was significantly greater than that in water, $51.7 \mathrm{~N} / \mathrm{mm}$, and that in $0.2 \mathrm{MPa}$ water, $51.2 \mathrm{~N} /$ $\mathrm{mm}$. The estimated tear strength of $\mathrm{EV}, 54.7 \mathrm{~N} / \mathrm{mm}$, was significantly greater than that of PO, $50.5 \mathrm{~N} / \mathrm{mm}$. The estimated tear strength in air after 1 week was significantly greater than that after 4 weeks; however, the estimated tear strength in $0.2 \mathrm{MPa}$ water after 1 week was significantly smaller than that after 4 weeks.

As for tear displacement, only the material significantly influenced the results. The tear displacement of PO, $152.9 \mathrm{~mm}$, was significantly greater than that of EV, $128.3 \mathrm{~mm}$.

\section{Water sorption and solubility}

The results for water sorption (WS) and solubility (SB) are shown in Table 4. Two-way ANOVA of WS revealed that the storage condition and material were significant factors affecting water sorption but that their interaction was not. The estimated WS in 0.2 $\mathrm{MPa}$ water, $3.1 \mathrm{mg}$, was significantly greater than that in water, $2.0 \mathrm{mg}$; the estimated WS of EV, $5.0 \mathrm{mg}$, was greater than that of $\mathrm{PO}, 0.1 \mathrm{mg}$.

With respect to the $\mathrm{SB}$, only the storage condition was a significant factor according to 2-way ANOVA. The estimated values of $\mathrm{SB}$ in water, $0.15 \mathrm{mg}$, was significantly greater than that in $0.2 \mathrm{MPa}$ water, -0.06 mg. 


\section{DISCUSSION}

The TMD problem related to the mouthpiece for divers has been reported more often for beginners than for experts $^{13)}$. Moreover, these TMD problems of the beginner diver have been reported to be improved when a custom-made mouthpiece for scuba diving is used ${ }^{19)}$. Therefore, the present study was conducted for diving conditions of beginner divers. According to the recommendations of organizations such as PADI and SSI, which issue certification cards for the Japanese association of scuba divers, the maximum depth of recreation for entry-level scuba divers should be less than $18 \mathrm{~m}$. Specimens were stored in $37^{\circ} \mathrm{C}$ water and in $37^{\circ} \mathrm{C}$ water under $0.2 \mathrm{MPa}$ pressure to simulate the oral cavity situation and underwater situation (approximately $20 \mathrm{~m}$ from the sea surface), respectively. The storage periods selected were 1 week and 4 weeks. If a recreation diver dives $20 \mathrm{~m}$ deep twice a week for 1 hour each time, 1 -week and 4-week storage could be considered to be 1.6- and 5.4-year usage of a mouthpiece for diving, respectively. However, actual mouthpieces are subjected to repeated pressure changes and repeated dry and wet stresses. These factors may reduce the durability of lamination and further research will be required to clarify them.

Bonding behavior of laminated thermoforming materials has been evaluated using several test methods such as the T-peel, $180^{\circ}$ peel, $90^{\circ}$ peel, and floating-roller methods. However, the T-shape shear test has been one of the most popular test methods and the bond strength at the fracture has been discussed ${ }^{16,17)}$. The load-displacement curve during the delamination test showed an S-shape (Fig. 4). The delamination started when the load rapidly increased. The load at the start of delamination is more important than the load at the final fracture. Consequently, not only the load at the final fracture but also that at the start of delamination were analyzed in the present study. These loads were designated 'BS at SD' and 'BS at FR', respectively. BS at $\mathrm{SD}$ of $\mathrm{EV}$ was significantly greater that of $\mathrm{PO}$, which suggests that the $\mathrm{EV}$ mouthpiece was more resistant to delamination than that made from PO. However, BS at FR was not significantly different regardless of the material used. Previous studies reported that BSs at FR were 12.7$14.4 \mathrm{~N} / \mathrm{mm}^{16)}$ for PO, and $7.4 \mathrm{~N} / \mathrm{mm}^{16)}$ and 1.46-5.4 $\mathrm{N}^{17}$ ) for ethylene-vinyl acetate copolymer materials. Regarding the $\mathrm{BS}$ at FR of $\mathrm{PO}$, the previously reported values were different from the values obtained in the present study ${ }^{17)}$. This was due to the different specimen preparation. The fracture pattern after the delamination test of $\mathrm{EV}$ was interfacial fracture; therefore, the bonding strength of $\mathrm{EV}$ could be improved if the laminate conditions were changed. One-third of the PO fracture pattern was cohesive fracture, which suggested sufficient adhesion of the two sheets. The ratios of $\mathrm{BS}$ at $\mathrm{SD}$ to $\mathrm{BS}$ at $\mathrm{FR}$ for $\mathrm{PO}$ were from 49 to $61 \%$, and smaller than those for EV. Moreover, the displacements at both SD and FR of PO were greater than those of EV. These results suggested that, compared with EV, PO could be easily deformed and elongated before and after the start of delamination.

Mechanical properties of mouth guard materials were evaluated by a tensile test and tear test. When the tensile test of a dumbbell-shaped mouth guard specimen material without a notch is performed, the specimen is sometimes pulled out of the grips due to great deformation during the test. Therefore, the tear test was used in the present study. With regard to storage conditions, the tear strength and BS at SD and FR in air were greater than those in water and 0.2 $\mathrm{MPa}$ water. Moreover, water sorption, even though slight, was observed after storage in water and 0.2 $\mathrm{MPa}$ water regardless of the material. This is why the $\mathrm{BS}$ and tear strength in water and 0.2 $\mathrm{MPa}$ water were significantly smaller than that in air.

The water storage period did not significantly influence the material properties examined in the present study. Regarding the effect of water immersion, the bonding strength of the EV material was not influenced by 23 or $37^{\circ} \mathrm{C}$ water immersion for 1 month $^{17)}$. The ratios of the BS at SD of PO in 0.2 $\mathrm{MPa}$ water to that in air were $84.2 \%$ for $1 \mathrm{w}$ and $83.9 \%$ for $4 \mathrm{w}$; those of $\mathrm{EV}$ were $82.7 \%$ for $1 \mathrm{w}$ and $80.7 \%$ for $4 \mathrm{w}$. These ratios showed a tendency to decrease with longer storage; however, the decreases were not large. These results suggest that BS might not decrease greatly after a longer period of storage.

The main constituents of mouthpieces for scuba diving are silicone-rubber materials according to the manufacturers. However, physical and mechanical properties of these materials have not been widely reported. The tear strength of polyolefin for mouthguard materials have been reported 27.6-65.5 N/ $\left.\mathrm{mm}(28.2-66.8 \mathrm{kgf} / \mathrm{cm})^{15}\right)$ and that of ethylene-vinyl acetate copolymer has been reported to be $47.1 \mathrm{~N} / \mathrm{mm}$ $(48 \mathrm{kgf} / \mathrm{cm})^{15)} \quad$ The tear strength of silicone-rubber materials for maxillofacial prostheses has been reported to be $4.0-35.5 \mathrm{~N} / \mathrm{mm}(4.1-36.2 \mathrm{kgf} / \mathrm{cm})^{20)}$, and those for impression materials to be $1.6-5.4 \mathrm{~N} / \mathrm{mm}$ (1.6-5.5 kgf/ $\mathrm{cm})$. The tear strengths of $\mathrm{PO}$ and $\mathrm{EV}$ in $0.2 \mathrm{MPa}$ water were $48.7-53.7 \mathrm{~N} / \mathrm{mm}$, which were greater than those above ${ }^{15)}$. Though there is no clear required value for bonding strength for the scuba-diving mouthpiece, the custom diving mouthpiece fabricated using the same method as in the present study shows adequate bonding behavior. Therefore, the obtained BS at SD and FR of $\mathrm{EV}$ and PO might be sufficient to withstand deformation during usage if an adequate area is laminated. Thus, both PO and EV can be employed for a custom diving mouthpiece.

In summary, the null hypothesis that the bonding strengths of $\mathrm{PO}$ and $\mathrm{EV}$ did not decrease after underwater condition storage was rejected. However, the bonding strength at the start of delamination after underwater storage ranged from 3.5 to $5.2 \mathrm{~N} / \mathrm{mm}$, which was more than $4 / 5$ of that in air. Further research is necessary to determine whether these 
values are sufficient for durability of the scuba-diving mouthpiece. Moreover, the test storage conditions in the vitro present study were only static. More dynamic storage conditions simulating occlusal force, the stress of waves, pressure changes or repeated dry and wet stresses should be considered for the actual usage of the scuba diving mouthpiece. These tests should be conducted in the future.

\section{REFERENCES}

1) Hirose $T$, Ono $T$, Nokubi $T$. Direction and magnitude of the load on the mouthpiece perceived by divers during scuba diving. J Sports Dent 2006; 9: 33-40.

2) Bove AA. Medical disorders related to diving. J Intensive Care Med 2002; 17: 75-86.

3) Pinto OF. Temporomandibular joint problems in underwater activities. J Prosthet Dent 1966; 16: 772-778.

4) Goldstein GR, Katz W. Divers mouth syndrome. N Y State Dent J 1982; 48: 523-525.

5) Grant SMB, Johnson F. Diver's mouth syndrome: a report of two cases and construction of custom-made regulator mouthpieces. Dent Update 1998; 25: 254-256.

6) Hobson RS. Temporomandibular dysfunction syndrome associated with scuba diving mouthpieces. Br J Sports Med 1991; 25: 49-51.

7) Roberts GV. Diver's mouth syndrome: a field study. Dent Update 2000; 27: 74-77.

8) Aldridge RD, Fenlon MR. Prevalence of temporomandibular dysfunction in a group of scuba divers. Br J Sports Med 2004; 38: 69-73.

9) Roydhouse N. 1001 disorders of the ear, nose and sinuses in scuba divers. Can J Appl Sport Sci 1985; 10: 99-103.

10) Hobson RS, Newton JP. Dental evaluation of scuba diving mouthpieces using a subject assessment index and radiological analysis of jaw position. Br J Sports Med 2001; 35: 84-88.

11) Koob A, Ohlmann B, Gabbert O, Klingmann C, Rammelsberg P, Schmitter M. Temporomandibular disorders in association with scuba diving. Clin J Sport Med 2005; 15: 359-363.

12) Hirose $T$, Ono $T$, Nagashima $T$, Nokubi T. The influence of scuba diving mouthpieces on the maxillo-oral system. $J$ Sports Dent 2003; 5: 1-10.

13) Hirose S, Ono T, Nagashima $T$, Nokubi T. Relationship between the breakage of mouthpiece and the experience in scuba diving. J Sports Dent 2004; 7: 52-57

14) Matsui R, Ueno T, Ohyama T. Fabrication of a custom diving mouthpiece using a thermoforming material. J Prosthet Dent 2004; 92: 392-394.

15) Maeda M. Study on mouth protectors-Physical properties of the polyolefin polymers. J Jpn Prosthodont Soc 1994, 38: 372-382.

16) Suzuki S, Harashima T, Asano T, Komiyama O, Kuroki T, Kusaka K, Kawara M. Use of polyolefin as mouthguard material as compared to ethylene vinyl acetate. Int J OralMed Sci 2007; 6: 14-18.

17) Takeda T, Ishigami K, Kawashima S, Nakajima K, Shimada A, Sumii T, Swan M. Adhesive strength and its improvement referring to the laminated-type mouthguard. Dent Traumatol 2006; 22: 205-214.

18) Kawasaki C, Sato N, Matsumoto M, Yasui T. Effect of heating temperature on mouthguard fittings. J Sports Dent 2002; 1: 25-29.

19) Ihara C, Matsui R, Yamanaka T, Saito S, Isoyama E, Ueno T. Provision of custom mouthpiece for a scuba diver affected by temporomandibular disorders related to diving. J Sports Dent 2007; 10: 108-113.

20) O'Brien WJ. Dental materials and their selection, 3rd ed, Quintessence Publishing Co, Carol Stream, IL, 2002, pp. 362-363. 